\title{
Influence of Environmental Humidity on Concrete Creep
}

\author{
Xihua Dai ${ }^{1, *}$, Xinmin Zhang ${ }^{1}$, Liangfang Liu $^{2}$, and Yidan Zou ${ }^{3}$ \\ ${ }^{1}$ Guangdong Highway Construction Co., Ltd., China \\ ${ }^{2}$ School of Civil and Architectural Engineering, Nanchang Institute of Technology, China \\ ${ }^{3}$ YaoHu Honors College, Nanchang Institute of Technology, China
}

\begin{abstract}
It is generally accepted that environment humidity as one of the environmental affects concrete creep considerably. The environmental humidity cycling, drying and high level humidity on concrete structures have significant effects on concrete creep. This paper studied the distribution of humidity field within concrete at both constant humidity condition and variable humidity condition using finite element method. It can be shown from the comparison that the finite element method has satisfied accuracy on simulation of interior humidity field of concrete. Coupled with the changing of humidity field within concrete and improved microprestress solidification theory, creep of concrete at constant environment humidity and different humidity levels was studied.
\end{abstract}

\section{Introduction}

Concrete is in the natural environment for a long time after pouring, and will be affected by relative humidity, carbon dioxide in the air and salt erosion in the water environment. The relative humidity has a great influence on the concrete. The influence of environmental relative humidity on concrete is mainly reflected in the movement of water in concrete and has certain influence on the properties of concrete (such as drying shrinkage and creep). The effect of relative humidity in the air on concrete is mainly due to changes in the relative humidity of the concrete caused by changes in air humidity. Neville ${ }^{[1]}$ pointed out that the concrete in the drying process had a larger creep variable than the concrete in a constant dry or wet state. The concrete creep variable at a relative humidity of $50 \%$ is approximately 2-3 times the relative humidity of $100 \%$. Concrete creep models considering humidity have been proposed in foreign countries, such as Committee European du Beton (CEB), American Concrete Institute (ACI) and Bazant.

The characteristics of these models are related to the influence of humidity on concrete creep and the drying shrinkage of concrete, so that the concrete shrinkage is used to obtain the prediction model of concrete creep under humidity. Bazant established a more comprehensive concrete creep model (BP model) ${ }^{[2]}$ considering humidity effect, and then introduced the BP$\mathrm{KX}$ model to explain the physical mechanism and physical concept of concrete creep under humidity change ${ }^{[3]}$. In 2004, Bazant proposed the theory of microprestressed consolidation and established the creep formula with the change of humidity, which can calculated the creep of concrete under any temperature and humidity history ${ }^{[4]}$.
At present, the research on the creep of concrete under the action of humidity is insufficient. Yuan ${ }^{[5]}$ combined early concrete moisture field and humidity diffusion theory to predict early concrete cracks. $\mathrm{Lu}^{[6]}$ established a creep model considering the actual working environment of concrete bridge by studying the environmental temperature and relative humidity of bridge, and pointed out the necessity of calculating the creep of concrete bridge by considering the temperature and humidity changes.

This paper analyzes the influence of humidity factors on the creep of concrete according to the change of humidity field in concrete and the improved microprestress consolidation theory. Furthermore, the creep law of concrete under the condition of constant humidity and the creep law of concrete under the condition of humidity change were calculated in compare with the test value.

\section{Numerical simulation of moisture field in concrete}

\subsection{Governing equation}

The calculation of humidity field can be summarized as solving partial differential control equation under certain geometric solution domain and certain solution domain boundary condition. The general form of partial differential equation is:

$$
A \Phi_{x x}+B \Phi_{x y}+C \Phi_{y y}=f\left(x, y, \Phi, \Phi_{x}, \Phi_{y}\right)
$$

Here, the coefficients $A, B$ and $C$ are constants, so the partial differential equation is called the approximate linear partial differential equation. If $B^{2}-4 A C<0$, then the

\footnotetext{
* Corresponding author: 18255670@qq.com
} 
above equation is called elliptic partial differential equation.If $B^{2}-4 A C>0$, then the above equation is called paraboloid partial differential equation. If $B^{2}-4 A C>0$, then the above equation is called hyperbolic partial differential equation.

The general form of humidity field control equation in concrete is:

$$
d \frac{\partial u}{\partial t}-\operatorname{div}(c \nabla u)+a u=f(x, t)
$$

If $c$ is related to the solution function $u$, that is $c=f(u)$, at this time, the equation is called nonlinear parabola partial differential equation, and the control equation of concrete humidity field is in this form. Thus, the general form of the control equation of concrete humidity field can be written:

$$
d \frac{\partial u}{\partial t}-c\left(\frac{\partial^{2} u}{\partial x_{1}^{2}}+\frac{\partial^{2} u}{\partial x_{2}^{2}}+\cdots+\frac{\partial^{2} u}{\partial x_{n}^{2}}\right)+a u=f(x, u)
$$

According to the above discussion, the control equation of macro humidity in cast-in-place concrete can be described by diffusion model. In cartesian coordinate system, the equation form is as follows:

$$
\begin{aligned}
& \frac{\partial}{\partial x}\left(D_{x} \frac{\partial h}{\partial x}\right)+\frac{\partial}{\partial y}\left(D_{y} \frac{\partial h}{\partial y}\right)+\frac{\partial}{\partial z}\left(D_{z} \frac{\partial h}{\partial z}\right)+ \\
& k_{h} \frac{\partial q}{\partial t}+k_{t} \frac{\partial T}{\partial t}=\frac{\partial h}{\partial t}
\end{aligned}
$$

Where $\omega$ means the water content per unit volume of concrete; $D_{x}, D_{y}, D_{z}$ are the diffusion coefficient in $x, y, z$ direction; $k_{h}, k_{t}$ are the influence parameters reflect the influence of hydration process and humidity change on humidity respectively; $h$ is the humidity distribution function.

If the anisotropic diffusion coefficient is considered to be equal, it can be simplified as $D(h)$. According to the recommended formula of European standard CEBFIP (90), under the condition of constant temperature, the humidity diffusion coefficient can be expressed as a function of the humidity $h(1 \geq h \geq 0)$ of the inner pore structure of concrete, as shown below.

$$
D(h)=D_{1}\left[\alpha+\frac{1-\alpha}{1+\left(\frac{1-h}{1-h_{c}}\right)^{n}}\right]
$$

Where $D_{1}$ means the maximum of $D(h)$, then $h=1.0 ; \alpha=D_{0} / D_{1}, \quad D_{0}$ is the minimum of $D(h)$, then $h=0.0 ; h_{c}$ means the humidity of $D(h)=0.5 D_{1} ; n$ is a constant. In the calculation process $\alpha, h_{c}, n$ can be respectively taken as $0.05,0.80$ and $15 . D_{1}$ can be determined by the following formula.

$$
D=\frac{D_{1.0}}{\frac{f_{c k}}{f_{c k 0}}}
$$

Where $\quad D_{1.0}=3.6 \times 10^{-6} \mathrm{~m}^{2} / h ; \quad f_{\mathrm{ck}}=10.0 M P a$. The characteristic compressive strength $f_{\text {ck }}$ can be estimated by average compressive strength $f_{\mathrm{cm}}$, which $f_{\mathrm{ck}}=f_{\mathrm{cm}}-8.0$.

\subsection{Boundary conditions}

From the above diffusion equation, the following boundary conditions can be obtained. On the boundary $S_{1}$ (Dirichlet boundary condition) .

$$
h(x, y, z, t)=h_{0}=\text { const }
$$

On the boundary $S_{2}$ (Neumann boundary condition).

$$
k_{x} \frac{\partial h}{\partial x} l_{x}+k_{y} \frac{\partial h}{\partial y} l_{y}+k_{z} \frac{\partial h}{\partial z} l_{z}+g\left(h-h_{\infty}\right)=0
$$

The modified Menzel equation can be adopted for the boundary diffusion function $g\left(h, h_{\infty}\right)$.

$$
g\left(h, h_{\infty}\right)=A(0.253+0.06 v)\left(h-h_{\infty}\right)
$$

Where the paremeter $A$ is an empirical coefficient; $v$ means the air flow rate.

\section{CREEP OF CONCRETE UNDER HUMIDITY}

Based on the theory of micro-prestressed consolidation, Bazant considered the creep of concrete under the influence of humidity and proposed the creep formula with the change of humidity, which can calculate the creep of concrete under the history of any humidity.

Under axial stress $\sigma$, the concrete strain $\varepsilon$ can be decomposed into the following form.

$$
\mathcal{E}=\varepsilon^{i}+\varepsilon^{v}+\varepsilon^{f}+\varepsilon^{c r}+\varepsilon^{s h}+\varepsilon^{T}
$$

Where $\varepsilon^{i}$ is the instantaneous strain ; $\varepsilon^{v}$ is the viscoelastic strain; $\varepsilon^{f}$ is the pure viscous strain; $\varepsilon^{c r}$ is the inelastic strain caused by cracking; $\varepsilon^{\text {sh }}$ is the humidity change causes shrinkage strain; $\varepsilon^{T}$ is the thermal strain caused by changes in humidity.

The instantaneous strain $\varepsilon^{i}$ is the instantaneous strain of axial stress, which can be expressed as $\varepsilon^{i}=q_{1} \sigma$. Coefficient $q_{1}$ under the condition of room temperature is $23^{\circ} \mathrm{C}$ and $h=h_{0}=1$, humidity that is nothing to do with aging.

The influence of temperature and humidity on the creep of concrete is shown in the following three aspects,

1) It affects the hydration process of cement and affects the maturity of concrete. These effects are expressed by the equivalent hydration time, which directly describes the degree of hydration.

2) The damage and reconstruction of transverse 
adhesion in the micro structure of concrete is affected, and the change in the rate of the destruction and reconstruction of the micro structure layer adhesion is described by reducing the time.

3) The influence of capillary water leads to the change of the separation pressure of the cementing hole, which leads to the change of micro-prestress in the microstructure and the change of shear slip rate on the shear surface.

$$
\begin{gathered}
t_{e}(t)=\int_{0}^{t} \beta(\tau) d \tau, \quad t_{r}(t)=\int_{0}^{t} \psi(\tau) d \tau \\
\beta(t)=\beta_{T}(t) \beta_{h}(t), \quad \beta_{h}(t)=\left\{1+\left[a_{h}-a_{h} h(t)\right]^{4}\right\}^{-1} \\
\beta_{T}(t)=\exp \left\{\frac{Q_{h}}{R}\left[\frac{1}{T_{0}}-\frac{1}{T(t)}\right]\right\}
\end{gathered}
$$

Moreover,

$$
\begin{gathered}
\psi(t)=\psi_{T}(t) \psi_{h}(t), \quad \psi_{h}(t)=\alpha_{h}+\left(1-\alpha_{h}\right) h(t)^{2} \\
\psi_{T}(t)=\exp \left\{\frac{Q_{v}}{R}\left[\frac{1}{T_{0}}-\frac{1}{T(t)}\right]\right\}
\end{gathered}
$$

Where $T_{0}$ is the reference temperature; $T$ is the actual ambient temperature; $h$ is the humidity content in capillary of cement slurry; $R$ is the gas constant; $Q_{\mathrm{h}}, Q_{\mathrm{v}}$ respectively correspond to the activation energy during hydration and viscosity processes. It hypothesis that $T_{0}=296 \mathrm{~K}, Q_{\mathrm{h}} / \mathrm{R} \approx 2700 \mathrm{~K}, Q_{\mathrm{v}} / \mathrm{R} \approx 5000 \mathrm{~K}$, and $a_{\mathrm{h}}=5, \alpha_{\mathrm{h}}=0.1$.

Humidity and temperature have effects on both the pure viscous strain rate and viscoelastic strain rate,

$$
\begin{gathered}
\dot{\varepsilon}^{e v}(t)=\frac{\dot{\gamma}(t)}{v\left[t_{e}(t)\right]} \\
\gamma(t)=\int_{0}^{t} \Phi\left[t_{r}(t)-t_{r}(\tau)\right] \dot{\sigma}(\tau) d \tau \\
\dot{\varepsilon}^{f}(t)=\frac{\psi(t)}{\eta(s)} \sigma(t) \\
\dot{S}+\psi_{s} c_{0} S^{2}=-k_{1}\left|\dot{T} \ln h+T \frac{\dot{h}}{h}\right|
\end{gathered}
$$

The definition and specific analysis of parameters above can be founded in the references[4] .

Shrinkage creep is caused by changes in capillary tension, surface tension and separation pressure, which are reduced by moisture entering or spilling out of the cement gel hole.

$$
\dot{\varepsilon}^{s h}(t)=k_{s h} \dot{h}(t)
$$

Where, the coefficient $k_{s h}$ is related to $h$. Thermal creep is caused by changes in humidity.

$$
\dot{\varepsilon}^{T}(t)=\alpha_{T} \dot{T}(t)
$$

Where, the thermal expansion coefficient $\alpha_{T}$ is little affected by $T$ and can be regarded as a constant. The damage creep involves the damage theory. Because the components calculated in this paper are small, the influence of this part on the creep of concrete can be ignored, so it is not discussed.

\section{CREEP LAW OF CONCRETE UNDER HUMIDITY}

First, the calculation parameters are as follows: $q_{1}=2.5 \times 10^{-5} / \mathrm{MPa}, \quad q_{2}=1.0 \times 10^{-4} / \mathrm{MPa}, \quad \alpha=0.015$, $q_{4}=6.0 \times 10^{-6} / \mathrm{MPa}, c=3.0 \times 10^{-8}(\mathrm{MPa} \cdot$ day $), K_{1}=3 \mathrm{MPa} / \mathrm{K}$. The calculation curve of concrete creep under different humidity conditions is shown in Fig. 1.

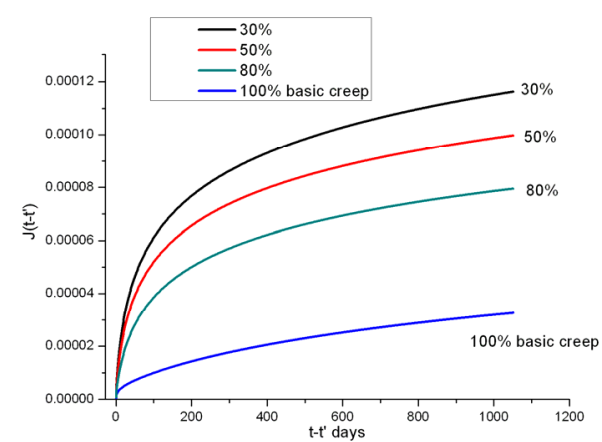

Fig.1. Concrete creep under different relative humidity

It can be seen from Figure 1 that the creep value of concrete varies greatly under different relative humidity conditions. The creep of concrete increases greatly under the condition of relative humidity of $80 \%, 50 \%$ and $30 \%$ compared with the basic creep of concrete under the condition humidity of $100 \%$. At the age of 1000 days, the creep value of concrete at a relative humidity of $30 \%$ is about 4 times that of concrete at a relative humidity of $100 \%$.

Troxel[ ${ }^{[7]}$ and Al-alusi ${ }^{[8]}$ both tested the effect of humidity on the creep of concrete. The experimental data of Troxell and Al-alusi are taken to verify the creep model of concrete under humidity. The specific parameters of Troxell test are as follows:

The concrete specimen is a cylinder of $100 \mathrm{~mm} \times 150 \mathrm{~mm}$, curing for 28 days, water cement ratio is 0.59 , aggregate cement ratio is 1:5.67. The specific parameters and processes of al-alusi test are as follows: the inner diameter of concrete cylinder is $127 \mathrm{~mm}$, the outer diameter is $152 \mathrm{~mm}$, and the length is $1.02 \mathrm{~m}$. At $100 \%$ relative humidity, temperature of $22.8^{\circ} \mathrm{C}$, maintenance and condition maintenance for 21 days; Concrete strength 24.8 $\mathrm{MPa}$, elastic modulus $23.6 \mathrm{GPa}$, mix ratio is water : cement : aggregate $=0.58: 1: 2$. Comparison between test data and model calculation curve is shown in Fig.2. 


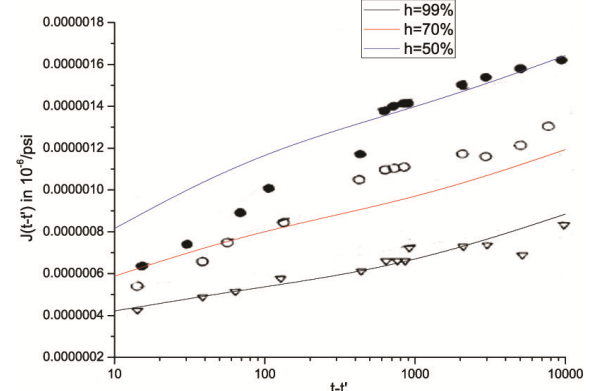

1) Troxell

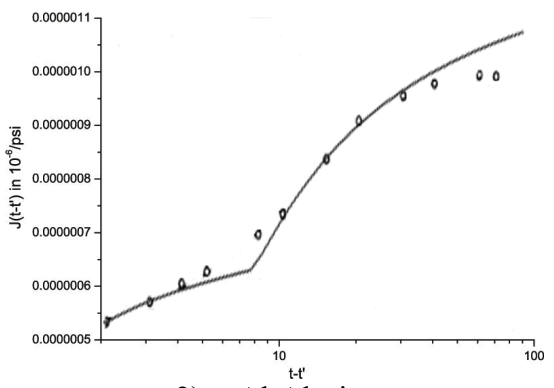

2) Al-Alusi

Fig.2. Comparsion between the calculation and test value

As can be seen from Figure 2, the calculation curve of concrete creep when relative humidity is $50 \%$ is in good agreement with the test data. In Troxell's test, the calculated curve deviated slightly from the test data when relative humidity was $99 \%$ and $70 \%$, and the calculated curve was in good agreement with the test data in general. In the experiment of Al-alusi, the creep rate of concrete increased greatly during the first humidity change, and the subsequent humidity circulation effect had no obvious influence on the creep rate of concrete. In addition, humidity variation has a great influence on creep of early age concrete. Therefore, the creep model of concrete under the condition of humidity is applicable to the calculation of creep under the condition of varying humidity.

\section{CONCLUSION}

1) The improved theoretical model of micro-prestressed consolidation proposed by Bazant can comprehensively consider the creep of concrete under the conditions of dynamic humidity and temperature changes. The physical meaning of the improved model is clear, and the calculated results are in good agreement with the engineering practice.

2) In actual environment, concrete is under the condition of dynamic change of environmental humidity. In general, it is impossible to obtain the analytic solution of concrete moisture field under complex boundary conditions. Therefore, the method of finite element numerical simulation can effectively calculate the transient humidity conduction process in concrete.

3) The creep of concrete humidity under constant humidity and varying humidity was analyzed. After calculation and analysis, the ultimate creep value of concrete under dry condition is 3-4 times of that under $100 \%$ humidity condition. The model calculation shows that the increase or decrease of humidity will cause the creep growth of concrete.

\section{References}

1. A.M. Neville, W.H. Dilger, J.J. Brooks. Creep of plain and structural concrete (Construction Press, 1983)

2. Z. P. Bazant, A. B. Hauggaard, S. Baweja. J. Eng. Mech, 123, 1188 (1997)

3. Z. P. Bazant, A. B. Hauggaard, S. Baweja. J. Eng. Mech, 123, 1195 (1997)

4. Z. P. Bazant, G. Cusatis, L. Cedolin. J. Eng. Mech, 130, 691 (2004)

5. Y. Yuan. Early crack control of concrete structures. (Science Press, Beijing, 2004)

6. Z.F. Lu, M.Y. Liu, Q. Li. J. Cent. South. Univ, 7, 2650 (2015)

7. G. E. Troxell, J. M. Raphael, R. E. Davis. ASTM Proceedings. (1958)

8. H. A-Alusi, V. Bertero, M. Polivka. Beton-Stahlbetonbau, 73, 18 (1978) 